\title{
PROPOSTA DE UM ÍNDICE DE PROFISSIONALIZAÇÃO POLÍTICA DAS FEDERAÇÕES SUBNACIONAIS DA INDÚSTRIA: FORMATOS INSTITUCIONAIS E PADRÕES DE ACOMPANHAMENTO DO PROCESSO LEGISLATIVO
}

\author{
José Augusto Hartmann ${ }^{1}$
}

\begin{abstract}
Resumo
Trata-se dos padrões de ação, especificamente, do acompanhamento do processo legislativo realizado pelas Federações Subnacionais da Indústria, objetivando contribuir com as discussões acerca da qualidade da atuação política do empresariado no Brasil em âmbito subnacional. Propõe-se que a qualidade da organização interna dessas entidades aponta para uma maior profissionalização política e, consequentemente, para uma maior capacidade de pressão. Para isso, verificou-se a organização interna das 27 Federações, avaliando-se sua estrutura de acompanhamento. Trata-se de uma pesquisa inicial, em que se buscou descrever comparativamente a organização para o acompanhamento do processo legislativo. A hipótese sugere que houve um processo de profissionalização política das Federações nos anos posteriores à redemocratização, conforme sugerido por parte da literatura. Foram avaliados nove atributos, compondo três categorias analíticas, isto é, aspectos que assinalam a i. sistematicidade, caracterizada por um processo de rotinização e complexificação da estrutura política interna, pelo ii. enraizamento, que indica relações com a sociedade, e, também, pela iii. transparência e empreendedorismo político de suas elites, uma vez que apontam para a sua capacidade de gerar respostas à sociedade. A presença desses itens compôs um índice de profissionalização política. Por essa avaliação descritiva, pode-se verificar esse processo de profissionalização das Federações, ainda que não homogêneo quando se considera o país. Verificou-se que pesa para uma maior profissionalização a sistematização e o enraizamento dessas entidades. Deste modo, enquanto a hipótese é confirmada ao menos em parte - a profissionalização não se desenvolve igualmente em todas as entidades -, aponta-se, contudo, para que o processo de profissionalização é mais antigo e remonta, pelo menos, ao decorrer do século XX, havendo necessidade de desenvolver um trabalho mais profundo de mapeamento de trajetórias.
\end{abstract}

Palavras-chave: Padrões de Acompanhamento; Federações Subnacionais da Indústria; Processo Legislativo; Profissionalização Política.

\section{INTRODUÇÃO}

Esta comunicação tem o objetivo de apresentar dados iniciais de uma pesquisa acerca da profissionalização política das Federações Subnacionais da Indústria. Relaciona-se, portanto, a

\footnotetext{
${ }^{1}$ Universidade Federal do Paraná, jahartmanncp@gmail.com, https://orcid.org/0000-0002-3027-4358.
} 
análise da organização do empresariado reunido nessas Federações, mais especificamente à organização interna dessas entidades sindicais, fato que antecede sua ação política.

São analisados os múltiplos casos (cross cases) das 27 Federações Estaduais e Distrital da Indústria (Federações), reunidas no sistema sindical de representação corporativista. Busca-se apresentar elementos significativos para o processo de profissionalização dessas entidades, assim como apresentar de modo panorâmico o estado desse processo em cada unidade federativa.

O objetivo, portanto, foi o de identificar e analisar a organização interna, que antecede e é fundamental para a ação política, dos empresários industriais reunidos nas Federações da Indústria, mais especificamente em sua relação com os legislativos subnacionais.

Trata-se de um estudo comparativo, em que se avalia os formatos institucionais que estabelecem os padrões de acompanhamento do processo legislativo em cada Federação. Aqui não se apresentam resultados do acompanhamento legislativo realizado por algumas dessas Federações, mas sua organização (mais ou menos) profissionalizada e capacidade institucional de acompanhamento do processo legislativo. As condições causais (variáveis independentes) analisadas não são avaliadas em termos de mais fortes ou fracas para a explicação do fenômeno, mas, conforme Mahoney e Thelen, são analisadas em termos de uma relação específica que permite a ocorrência do fenômeno (MAHONEY; THELEN, 2015, p. 9).

A hipótese que embasa a pesquisa é da existência de um processo de profissionalização política das Federações Subnacionais da Indústria no Brasil, solidificado nos anos seguintes à redemocratização, sobretudo pós-1988. Decorre disso o recorte temporal entre 1988 e 2018. A sugestão dessa conjuntura crítica parte das considerações realizadas por Bresser-Pereira e Eli Diniz, que destacaram o papel do empresariado reunido nas Federações Subnacionais da Indústria como ator político de êxito, sobretudo a partir dos primeiros anos deste século (BRESSER-PEREIRA; DINIZ, 2009, p. 95).

\section{FORMATOS INSTITUCIONAIS E PADRÕES DE ACOMPANHAMENTO DO PROCESSO LEGISLATIVO}

Deste modo, consideramos que as causas da organização política das entidades sindicais podem ser, em alguma medida, explicadas pelas interações interinstitucionais que englobam seus formatos institucionais e suas estratégias ou padrões de ação política. 
Para isso, a análise das Federações foi realizada, sobretudo, por meio de técnicas qualitativas sustentadas no método comparativo e ancoradas nas técnicas do Qualitative Comparative Analysis (QCA) (COLLIER, 2011; RAGIN, 1987). Entretanto, não se realizou o teste de QCA. Os dados foram relacionados e calibrados, estabelecendo um índice de profissionalização política pela avaliação dos graus de pertencimento às categorias.

Deste modo, propusemos a combinação de procedimentos comparativos com uma perspectiva compreensiva, uma vez que, tal como afirma Perissinotto, "o procedimento comparativo não esgota o empreendimento científico nas ciências sociais, já que revelar as causas dos fenômenos sociais não implica revelar como eles são produzidos" (PERISSINOTTO, 2013, p. 152).

Note-se que, via de regra, uma vez que analisamos o mesmo fenômeno nos 27 (múltiplos)casos, seguimos a tradição do método da semelhança, buscando as causas da profissionalização política. Contudo, uma vez que coexistem graus diversos dessa profissionalização, também apontamos aspectos verificados por meio do método indireto (pois não experimental) da diferença, em que elementos presentes unicamente nos casos positivos são aventados (PERISSINOTTO, 2013). A partir dessa observação, pudemos compor um índice de profissionalização política para as Federações.

Em vista disso, trata-se de um modelo ideal-típico definido em três níveis, desde 1. o amadorismo e/ou diletantismo, caracterizado pela ausência de itens verificados (profissionalização baixa), 2. Profissionalização média, até 3. um alto grau de Profissionalização Política.

O índice de profissionalização política foi composto por aspectos que assinalam tanto a i. sistematicidade, isto é, um processo de rotinização e complexificação da estrutura política interna (PANEBIANCO, 2005), quanto de ii. enraizamento, que indica relações com a sociedade (DAZA, 2005). Além disso, também consideramos aspectos de iii. transparência e empreendedorismo político de suas elites, uma vez que apontam para a sua capacidade de gerar respostas à sociedade (ALCÁNTARA-SÁEZ, 2016; HARDIN, 1982).

A estrutura do índice foi pautada nas sugestões de Earl Babbie, que afirma como escolha mais segura a indicação de mesmo peso para cada variável de sua constituição, atribuindo-se um escore proporcionalmente (BABBIE, 1999). Estudos sobre profissionalização parlamentar também contribuíram para pensarmos essa estrutura, ainda que as variáveis não sigam os mesmos dados, uma vez que buscamos sua relação com um processo de burocratização/institucionalização (SQUIRE, 1992). 
Essas três categorias analíticas foram estruturadas a partir de nove atributos - três para cada categoria, dispostos respectivamente às categorias de sistematização, enraizamento e transparência/empreendedorismo a seguir: i. a formulação de Departamentos Legislativos ou correspondentes; ii. a produção de Agendas Legislativas Estaduais/Distrital da Indústria (ALEI); iii. a produção de ALEI por pelo menos quatro anos (tempo de uma legislatura); iv. produção ininterrupta de ALEI na última legislatura (produção atual); v. candidaturas em eleições municipais, estaduais ou federais por presidentes de Federações; vi. participação na presidência ou vicepresidência da Confederação Nacional da Indústria (CNI) por presidentes de Federações; vii. institucionalização de Departamentos de Assuntos Sociais ou correlatos; a viii. disponibilidade de acesso as ALEI (pelo menos quatro); e ix. o retorno/pareceres das ações realizadas no período anterior.

Os resultados obtidos confirmam um processo de profissionalização das Federações do modelo corporativista subnacional brasileiro, especialmente a partir da primeira década do século corrente, assim como uma crescente preocupação com os legislativos subnacionais, o que corrobora com a tese da profissionalização política dessas Federações e distancia-se das teses da "debilidade política da indústria" (MANCUSO, 2007) e do "ultrapresidencialismo estadual" (ABRÚCIO, 1998).

Ainda assim, observa-se que esse processo de profissionalização não se dá de modo homogêneo, havendo algumas condições necessárias para o desenvolvimento desse processo.

Ainda assim, de modo geral, pode-se observar da organização interna um crescimento da produção e divulgação de Agendas Legislativas Estaduais/Distrital da Indústria (ALEI) desde que a primeira (Espírito Santo) foi divulgada em 2003. Desde então, 13 Federações publicam ou publicaram essa Agenda. Apenas 8 Federações não apresentam Departamentos Legislativos ou correspondentes e 14 têm Departamentos de Assuntos Sociais, apresentando algum direcionamento para a sociedade, que pode ser compreendido para além de um aspecto do enraizamento, como um outside lobby (KANOL, 2014). Quando se trata de candidaturas e participação na presidência da Confederação Nacional, aspecto do empreendedorismo político, em 15 Federações se localizou diretores na presidência da CNI - sobretudo das Federações com maior representação sobre PIB e antiguidade. Candidatos a cargos eletivos originados das diretorias de Federações, mais especificamente presidentes e/ou vices, representaram 12 Federações diversas, seja em eleições municipais, estaduais ou federais. Nesse último caso, deu-se de modo mais difuso, ainda que entre as doze, grande parte fora de Federações profissionalizadas. 
Dessa maneira, de modo amplo, tem-se que as Federações se encontram em um processo de desenvolvimento de um protagonismo político, com a presença, em boa medida, de Departamentos Legislativo e Agendas Legislativas, o que indica o acompanhamento dos decisores nas unidades federadas - não somente da negociação direta com governadores ou burocracia - e a publicização de suas preferências. Deste modo, a organização política das Federações subnacionais promoveu uma ação política mais complexa e autônoma, para além da participação nas instâncias da CNI, em destaque a RedIndústria.

Também, verificamos que presidentes das Federações, em boa medida, buscaram saltos mais longos em suas carreiras, seja em cargos eletivos ou na CNI, embora o problema de pesquisa se refira à dimensão local da ação parlamentar dos industriais, o que indica o empreendedorismo político dessas diretorias, utilizando-se do prestígio dessas entidades e confundindo suas carreiras com a própria ação das entidades que inicialmente representam - gerando-se ganhos para ambos.

Ao encontro das variáveis explicativas, verificamos a tendência de maior profissionalização entre as Federações que representam unidades federativas de maior peso no conjunto do PIB industrial brasileiro, assim como uma tendência a se encontrar entidades mais jovens com menor profissionalização política, o que remete à importância da antiguidade na consolidação dessas entidades.

Cabe destacar que as Federações atuam para apoiar o trabalho de acompanhamento legislativo da CNI, entretanto cada uma deve, por conta própria, realizar seu trabalho político nas unidades federativas - o que revela o grande esforço que realizam para efetivar suas ações políticas no ambiente subnacional, o que não as fazem negligenciar, como visto, esse locus.

\section{3. ÍNDICE DE PROFISSIONALIZAÇÃO POLÍTICA}

Nesta seção, os dados que são utilizados para estabelecer o índice de profissionalização política são expostos. Cabe notar que, ainda que se faça uma calibragem dos dados a partir dos atributos, não se realiza um teste de QCA.

A primeira tabela apresenta os dados relativos à Sistematização. Nessa tabela, pode-se verificar, por uma classificação booliana, a presença/ausência nas Federações, organizadas por Unidade da Federação, de Departamento Legislativo, Publicação de Agenda Legislativa Estadual/Distrital da Indústria (ALEI) e Produção e Publicação dessa ALEI por, pelo menos 4 anos. 
I Seminário Discente de Ciência Política (SDCP)

Programa de Pós-Graduação em Ciência Política (PPGCP)

Universidade Federal do Paraná (UFPR)

Curitiba, 20 a 21 de agosto de 2020

QUADRO 1 - SISTEMATIZAÇÃO

\begin{tabular}{|c|c|c|c|c|}
\hline FEDERAÇÃO & $\begin{array}{c}\text { PRESENÇA DE } \\
\text { DEPARTAMENTO } \\
\text { LEGISLATIVO }\end{array}$ & $\begin{array}{c}\text { PRODUÇÃO E } \\
\text { PUBLICAÇÃO DE } \\
\text { ALEI }\end{array}$ & $\begin{array}{l}\text { PRODUÇÃO PELO } \\
\text { PERÍODO DE } 4 \\
\text { ANOS }\end{array}$ & SOMA \\
\hline SP & 1 & $\begin{array}{l}\text { Não tem ALEI e/ou } \\
\text { não divulga }(0)\end{array}$ & 0 & 1 \\
\hline RJ & 1 & $\begin{array}{c}\text { Tem ALEI desde } \\
\text { 2005, mas } \\
\text { disponibiliza apenas } \\
\text { últimas } 4(1)\end{array}$ & 1 & 3 \\
\hline $\mathrm{MG}$ & 1 & $\begin{array}{l}\text { Tem ALEI, mas sem } \\
\text { informações. Divulga } \\
\text { apenas última (1) }\end{array}$ & 1 & 3 \\
\hline PR & 1 & & & \\
\hline & $\begin{array}{c}\text { Tem ALEI desde } \\
2005 \text { (com falhas em } \\
2015 \text { e 2016). } \\
\text { Disponibiliza demais } \\
\text { (1) }\end{array}$ & 1 & 3 & 1 \\
\hline $\mathrm{RS}$ & 1 & $\begin{array}{c}\text { Tem ALEI, mas sem } \\
\text { informações. Divulga } \\
\text { apenas a partir de } \\
2017(1)\end{array}$ & 1 & 3 \\
\hline $\mathrm{SC}$ & 1 & $\begin{array}{c}\text { Tem ALEI desde } \\
\text { 2008. Disponibiliza } \\
\text { todas desde } 2012(1)\end{array}$ & 1 & 3 \\
\hline $\mathrm{BA}$ & 1 & $\begin{array}{c}\text { Tem ALEI desde } \\
\text { 2013. Divulga todas } \\
\text { (1) }\end{array}$ & 1 & 3 \\
\hline GO & 1 & $\begin{array}{l}\text { Teve ALEI entre } \\
2005 \text { e 2013. Não } \\
\text { produz, mas tem } \\
\text { acompanhamento } \\
\text { interno (1) }\end{array}$ & 1 & 3 \\
\hline PA & 0 & $\begin{array}{l}\text { Não tem ALEI e/ou } \\
\text { não divulga (0) }\end{array}$ & 0 & 0 \\
\hline ES & 1 & $\begin{array}{c}\text { Tem ALI desde } \\
\text { 2003, mas } \\
\text { disponibilizou } \\
\text { somente até } 2009(1)\end{array}$ & 1 & 3 \\
\hline $\mathrm{PE}$ & 0 & $\begin{array}{l}\text { Não tem ALEI e/ou } \\
\text { não divulga (0) }\end{array}$ & 0 & 0 \\
\hline AM & 1 & $\begin{array}{l}\text { Não tem ALEI e/ou } \\
\text { não divulga (0) }\end{array}$ & 0 & 1 \\
\hline $\mathrm{CE}$ & 1 & $\begin{array}{l}\text { Não tem ALEI e/ou } \\
\text { não divulga (0) }\end{array}$ & 0 & 1 \\
\hline MT & 1 & $\begin{array}{l}\text { Não tem ALEI e/ou } \\
\text { não divulga (0) }\end{array}$ & 0 & 1 \\
\hline MS & 0 & $\begin{array}{l}\text { Não tem ALEI e/ou } \\
\text { não divulga (0) }\end{array}$ & 0 & 0 \\
\hline MA & 0 & $\begin{array}{l}\text { Não tem ALEI e/ou } \\
\text { não divulga (0) }\end{array}$ & 0 & 0 \\
\hline $\mathrm{RN}$ & 1 & $\begin{array}{c}\text { Tem ALEI desde } \\
\text { 2014, mas divulgou } \\
\text { somente a primeira } \\
\text { (1) }\end{array}$ & 0 & 2 \\
\hline $\mathrm{DF}$ & 1 & Tem ALEI e & 1 & 3 \\
\hline
\end{tabular}




\begin{tabular}{|c|c|c|c|c|}
\hline & & $\begin{array}{c}\text { disponibiliza desde } \\
2008(1)\end{array}$ & & \\
\hline SE & 1 & $\begin{array}{l}\text { Tem ALEI. Divulgou } \\
\text { somente primeira (1) }\end{array}$ & 0 & 2 \\
\hline PB & 0 & $\begin{array}{l}\text { Não tem ALEI e/ou } \\
\text { não divulga }(0)\end{array}$ & 0 & 0 \\
\hline $\mathrm{AL}$ & 0 & $\begin{array}{l}\text { Não tem ALEI e/ou } \\
\text { não divulga }(0)\end{array}$ & 0 & 0 \\
\hline RO & 0 & $\begin{array}{l}\text { Não tem ALEI e/ou } \\
\text { não divulga }(0)\end{array}$ & 0 & 0 \\
\hline PI & 1 & $\begin{array}{l}\text { Não tem ALEI e/ou } \\
\text { não divulga }(0)\end{array}$ & 0 & 1 \\
\hline TO & 1 & $\begin{array}{l}\text { Tem ALEI desde } \\
\text { 2006, disponibiliza } \\
\text { desde } 2007 \text { (com } \\
\text { lacunas em 2014, } \\
2015 \text { e 2016) (1) }\end{array}$ & 1 & 3 \\
\hline RR & 1 & $\begin{array}{l}\text { Não tem ALEI e/ou } \\
\text { não divulga (0) }\end{array}$ & 0 & 1 \\
\hline
\end{tabular}

FONTE: O autor (2020).

Esta tabela aponta para uma Sistematização consolidada nas Federações de RJ, MG, PR, RS, SC, BA, GO, ES, RN, DF, SE e TO. Essas Federações apresentam, quando não os três atributos, pelo menos a presença de Departamento Legislativo e Produção de ALEI, o que sugere a necessidade desses atributos. Nesse caso, um teste futuro de QCA pode contribuir para essa avaliação.

A tabela de Enraizamento apresenta os seguintes dados:

QUADRO 2 - ENRAIZAMENTO

\begin{tabular}{|c|c|c|c|c|}
\hline FEDERAÇÃO & $\begin{array}{c}\text { DISPONIBILIZAÇÃO } \\
\text { DE ALEI POR } 4 \\
\text { ANOS NA WEB }\end{array}$ & $\begin{array}{l}\text { DEPARTAMENTO } \\
\text { DE ASSUNTOS } \\
\text { SOCIAIS }\end{array}$ & $\begin{array}{c}\text { PRODUÇÃO DE } \\
\text { ALEI NA ÚLTIMA } \\
\text { LEGISLATURA (4 } \\
\text { ANOS) }\end{array}$ & SOMA \\
\hline SP & 0 & 1 & 0 & 1 \\
\hline RJ & 1 & 1 & 1 & 3 \\
\hline $\mathrm{MG}$ & 0 & 0 & 0 & 0 \\
\hline PR & 0 & 1 & 1 & 2 \\
\hline $\mathrm{RS}$ & 0 & 1 & 0 & 1 \\
\hline $\mathrm{SC}$ & 1 & 0 & 1 & 2 \\
\hline BA & 1 & 1 & 1 & 3 \\
\hline GO & 0 & 1 & 1 & 2 \\
\hline $\mathrm{PA}$ & 0 & 1 & 0 & 1 \\
\hline $\mathrm{ES}$ & 0 & 1 & 1 & 2 \\
\hline $\mathrm{PE}$ & 0 & 0 & 0 & 0 \\
\hline $\mathrm{AM}$ & 0 & 0 & 0 & 0 \\
\hline $\mathrm{CE}$ & 0 & 1 & 0 & 1 \\
\hline MT & 0 & 1 & 0 & 1 \\
\hline
\end{tabular}




\begin{tabular}{|c|l|l|l|l|}
\hline MS & 0 & 1 & 0 & 1 \\
\hline MA & 0 & 0 & 0 & 0 \\
\hline RN & 0 & 1 & 0 & 1 \\
\hline DF & 1 & 0 & 0 & 0 \\
\hline SE & 0 & 0 & 0 & 0 \\
\hline PB & 0 & 0 & 0 & 0 \\
\hline AL & 0 & 0 & 0 & 0 \\
\hline RO & 0 & 1 & 0 & 1 \\
\hline PI & 0 & 0 & 1 & 0 \\
\hline TO & 0 & 0 & 0 & 0 \\
\hline RR & 0 & 0 & 0 & \\
\hline AP & 0 & 0 & & \\
\hline
\end{tabular}

FONTE: O autor (2020).

Nesse caso, há um menor número de Federações identificadas. Especificamente, tem-se RJ, PR, SC, BA, GO, ES e DF. As Federações que apresentam enraizamento, têm em comum a atualidade de seu acompanhamento legislativo, identificado pela presença de ALEI na última legislatura (durante os 4 anos).

O enraizamento pode ser entendido como uma categoria central, uma vez que somente Federações com maior complexificação do acompanhamento apresentariam esses valores.

Quanto à Transparência/Empreendedorismo Político, tem-se o seguinte:

\begin{tabular}{|c|c|c|c|c|}
\hline FEDERAÇÃO & $\begin{array}{l}\text { PRESIDÊNCIA DA } \\
\text { CNI }\end{array}$ & CANDIDATURA & $\begin{array}{c}\text { PARECER DAS } \\
\text { AÇÕES }\end{array}$ & SOMA \\
\hline SP & 1 & 1 & 0 & 2 \\
\hline RJ & 1 & 0 & 0 & 1 \\
\hline MG & 1 & 0 & 0 & 1 \\
\hline PR & 1 & 1 & 0 & 2 \\
\hline $\mathrm{RS}$ & 1 & 0 & 0 & 1 \\
\hline $\mathrm{SC}$ & 1 & 0 & 1 & 2 \\
\hline BA & 0 & 0 & 0 & 0 \\
\hline GO & 1 & 1 & 0 & 2 \\
\hline PA & 1 & 0 & 0 & 1 \\
\hline ES & 1 & 1 & 0 & 2 \\
\hline $\mathrm{PE}$ & 0 & 1 & 0 & 1 \\
\hline $\mathrm{AM}$ & 1 & 1 & 0 & 2 \\
\hline $\mathrm{CE}$ & 1 & 1 & 0 & 2 \\
\hline MT & 1 & 0 & 0 & 1 \\
\hline MS & 0 & 1 & 0 & 1 \\
\hline MA & 0 & 0 & 0 & 0 \\
\hline $\mathrm{RN}$ & 1 & 0 & 0 & 1 \\
\hline $\mathrm{DF}$ & 0 & 0 & 0 & 0 \\
\hline
\end{tabular}




\begin{tabular}{|c|l|l|l|l|}
\hline SE & 1 & 0 & 0 & 1 \\
\hline PB & 0 & 0 & 0 & 0 \\
\hline AL & 0 & 0 & 0 & 0 \\
\hline RO & 0 & 0 & 0 & 2 \\
\hline PI & 1 & 1 & 0 & 1 \\
\hline TO & 0 & 1 & 0 & 0 \\
\hline RR & 0 & 0 & 0 & 1 \\
\hline AP & 0 & 1 & 0 & \\
\hline
\end{tabular}

FONTE: O autor (2020).

As Federações que apresentam esses atributos são as de SP, SC, GO, ES, AM, CE e PI. Em comum entre essas Federações, a presença de suas diretorias na presidência (ou vice-presidência) da Confederação Nacional da Indústria (CNI). Há, ainda, uma grande cobertura para presidentes dessas Federações que foram candidatos à cargos eletivos. Isso não ocorreu somente em SC, que, por outro lado, foi o único estado a apresentar parecer das ações realizadas em relação aos interesses manifestos em ALEI anterior - denotando maior transparência, que pode ser identificada como a variável mais atípica e laboriosa para se conseguir, dada sua raridade.

Deste modo, pode-se verificar a seguinte disposição para a profissionalização política dessas Federações:

QUADRO 4 - PROFISSIONALIZAÇÃO POLÍTICA

\begin{tabular}{|c|c|c|c|c|}
\hline FEDERAÇÃO & Sistematização & Enraizamento & $\begin{array}{c}\text { Transparência/ } \\
\text { Ambição }\end{array}$ & $\begin{array}{c}\text { Soma das } \\
\text { pontuações }\end{array}$ \\
\hline São Paulo & 1 & 1 & 2 & 4 \\
\hline Rio de Janeiro & 3 & 3 & 1 & 7 \\
\hline Minas Gerais & 3 & 0 & 1 & 4 \\
\hline Paraná & 3 & 2 & 2 & 7 \\
\hline Rio Grande do Sul & 3 & 1 & 1 & 5 \\
\hline Santa Catarina & 3 & 2 & 2 & 7 \\
\hline Bahia & 3 & 3 & 0 & 6 \\
\hline Goiás & 3 & 2 & 2 & 7 \\
\hline Pará & 0 & 1 & 1 & 2 \\
\hline Espírito Santo & 3 & 2 & 2 & 7 \\
\hline Pernambuco & 0 & 0 & 1 & 1 \\
\hline Amazonas & 1 & 0 & 2 & 3 \\
\hline Ceará & 1 & 1 & 2 & 4 \\
\hline Mato Grosso & 1 & 1 & 1 & 3 \\
\hline Mato Grosso do Sul & 0 & 1 & 1 & 2 \\
\hline Maranhão & 0 & 0 & 0 & 0 \\
\hline Rio Grande do Norte & 2 & 1 & 1 & 4 \\
\hline Distrito Federal & 3 & 2 & 0 & 5 \\
\hline Sergipe & 2 & 0 & 1 & 3 \\
\hline
\end{tabular}




\begin{tabular}{|c|l|l|l|l|}
\hline Paraíba & 0 & 0 & 0 & 0 \\
\hline Alagoas & 0 & 0 & 0 & 0 \\
\hline Rondônia & 0 & 1 & 0 & 1 \\
\hline Piauí & 1 & 0 & 2 & 3 \\
\hline Tocantins & 3 & 1 & 0 & 1 \\
\hline Roraima & 1 & 0 & 1 & 1 \\
\hline Amapá & 0 & 0 & & \\
\hline
\end{tabular}

FONTE: O autor (2020).

As Federações profissionalizadas identificadas foram as de RJ, PR, RS, SC, BA, GO, ES, DF e TO. A calibragem dos dados foi realizada do seguinte modo: a soma das pontuações de cada Federação pode variar entre 0 e 9. Para gerar uma variável de resultado binária foi atribuída às linhas que somarem valores entre 0 e 4 o valor 0 (ausência do fenômeno) e para as linhas que somarem entre 5 e 9, a pontuação 1 (presença do fenômeno).

Por fim, pode-se avaliar o grau de profissionalização dessas Federações. Isto deve-se a possibilidade de se observar uma Federação considerada profissionalizada que tenha seus atributos concentrados em uma única categoria (como é o caso da Fiergs), sendo considerada de baixa profissionalização. Por outro lado, algumas Federações apresentam a presença de vários atributos, distribuídos nas categorias (como as Federações do PR, SC e ES), consideradas de alta profissionalização.

Essa classificação foi exposta do seguinte modo:

QUADRO 5 - PARAMETRIZAÇÃO DAS CATEGORIAS ANALÍTICAS

\begin{tabular}{|c|c|c|}
\hline $0-1$ & 2 & 3 \\
\hline NÍVEL BAIXO - AMADORISMO E/OU & NÍVEL MÉDIO - COM & NÍVEL ALTO - \\
DILETANTISMO & MÉDIA & PROFISSIONALIZADA \\
& PROFISSIONALIZAÇÃO & \\
\hline
\end{tabular}

FONTE: O autor (2020).

Os das categorias foram utilizados nessa parametrização da seguinte maneira: nível baixo para aquelas entidades que apresentaram ausência ou presença de apenas um dos atributos; nível médio para aquelas que apresentaram a presença de dois atributos e; nível alto para aquelas que apresentaram os três atributos.

Assim, quando avaliamos os graus dessa profissionalização, considerando-se os outcomes das três categorias (Sistematização, Enraizamento e Transparência/Empreendedorismo político), encontramos o seguinte: 
QUADRO 6 - GRAU DE PROFISSIONALIZAÇÃO POLÍTICA

\begin{tabular}{|c|c|c|c|c|}
\hline FEDERAÇ̃̃O & Sistematização & Enraizamento & $\begin{array}{c}\text { Transparência/ } \\
\text { Empreendedorismo }\end{array}$ & $\begin{array}{c}\text { Soma das } \\
\text { pontuaç̃es }\end{array}$ \\
\hline São Paulo & 0 & 0 & 1 & 2 \\
\hline Rio de Janeiro & 1 & 1 & 0 & 1 \\
\hline Minas Gerais & 1 & 0 & 0 & 3 \\
\hline Paraná & 1 & 1 & 1 & 3 \\
\hline Rio Grande do Sul & 1 & 0 & 0 & 2 \\
\hline Santa Catarina & 1 & 1 & 1 & 3 \\
\hline Bahia & 1 & 1 & 0 & 0 \\
\hline Goiás & 1 & 1 & 1 & 3 \\
\hline Pará & 0 & 0 & 0 & 1 \\
\hline Espírito Santo & 1 & 1 & 1 & 0 \\
\hline Pernambuco & 0 & 0 & 0 & 0 \\
\hline Amazonas & 0 & 0 & 0 & 0 \\
\hline Ceará & 0 & 0 & 0 & 1 \\
\hline Mato Grosso & 0 & 0 & 0 & 2 \\
\hline Mato Grosso do Sul & 0 & 0 & 0 & 1 \\
\hline Maranhão & 0 & 0 & 0 & 0 \\
\hline Rio Grande do Norte & 1 & 1 & 0 & 0 \\
\hline Distrito Federal & 1 & 0 & 0 & 0 \\
\hline Sergipe & 1 & 0 & 0 & 1 \\
\hline Paraíba & 0 & 0 & 0 & 0 \\
\hline Alagoas & 0 & 0 & 0 & 0 \\
\hline Rondônia & 0 & 0 & 0 & 0 \\
\hline Piauí & 0 & 0 & 0 & 0 \\
\hline Tocantins & 1 & 0 & 0 & 0 \\
\hline Roraima & 0 & 0 & 0 & 0 \\
\hline Amapá & 0 & 0 & 0 & 0 \\
\hline
\end{tabular}

FONTE: O autor (2020).

Verificou-se 20 Federações com baixa profissionalização política: SP, MG, RS, PA, PE, AM, CE, MT, MS, MA; RN, SE, PB; AL, RO, PI, TO, RR, AP e AC. As 7 restantes, com média e alta profissionalização, foram as de RJ, BA e DF (Média), PR, SC, GO e ES (Alta).

As três Federações com média profissionalização política apresentaram dados de sistematização e enraizamento. Nenhuma delas reuniu os atributos para transparência/empreendedorismo, o que aponta para o caráter contingente dessa condição, pelo menos para uma profissionalização neste nível. 


\title{
4. CONSIDERAÇÕES FINAIS
}

É possível inferir que o sistema corporativista de representação patronal se configurou como uma sustentação para a organização dessas entidades, pelo menos no período pós-autoritário, de maior profissionalização, assim como para a ação política empresarial (OLSON, 2011).

Consequentemente, esse sistema (entidades sindicais) não se caracterizou como impeditivo, o que já fora afirmado por parte da literatura, mesmo para o período democrático anterior a 1964 (COSTA, 1998; LEOPOLDI, 2000) tal como para o período pós-Ditadura (MANCUSO, 2007). Pelo contrário, apresentou-se compatível com a democracia, possibilitando a ação de grupos de interesse e capazes de privilegiar a organização política de uma parcela do empresariado brasileiro.

Os achados também indicam o interesse dessas entidades em dispender recursos para o acompanhamento legislativo e, logo, na maior parte das unidades federadas do país, a preocupação com os legislativos locais - o que corrobora com as críticas ao modelo do "ultrapresidencialismo estadual" (TOMIO; RICCI, 2012).

Verificamos, uma organização, via de regra, profissional e não apenas focada na relação insulada com uma burocracia. As Federações se apresentaram atentas aos legislativos subnacionais com lideranças participando ativamente do jogo político (inclusive com candidaturas).

Quanto às categorias, percebeu-se que enquanto transparência/empreendedorismo político não se apresentam como necessárias para o processo de profissionalização, sistematização e enraizamento são vistas em todas as Federações com níveis Médio e Alto de profissionalização.

\section{REFERÊNCIAS}

ABRÚCIO, Fernando Luiz. O ultrapresidencialismo estadual. In: ANDRADE, Regis de Castro (org.). Processo de Governo no Município e no Estado. São Paulo: EdUSP, 1998. p. 87-116.

\author{
ALCÁNTARA-SÁEZ, Manuel A. A profissionalização da política. Curitiba: \\ CPOPPPGCP/UFPR. 2016.
}

BABBIE, Earl. Métodos de Pesquisa de Survey. Belo Horizonte: Ed. UFMG, 1999.

BRESSER-PEREIRA, Luiz Carlos; DINIZ, Eli. Empresariado Industrial, Democracia e Poder Político. Novos Estudos - CEBRAP, São Paulo, nº.84, p.83-99, 2009. 
COLLIER, David. Teaching Process Tracing: Exemples and Exercises. Political Science and Politics, Cambrige, v. 44, n. 4, p. 823-830, 2011.

COSTA, Paulo Roberto N. Democracia nos anos 50: burguesia comercial, corporativismo e parlamento. São Paulo: Hucitec, 1998.

DAZA, Javier. D. La institucionalización partidista: una propuesta de abordaje de las estructuras organizativas partidistas. Estudios Políticos. No 27. Medellín, jul-dez. 2005, p. 103-127.

HARDIN, Russell. Collective action. In: Collective action. Baltimore: The Johns Hopkins University Press, 1982. p. 16-37.

KANOL, Direnç. Outside Lobbying and Policy Change: The Role of Incumbents' Ideology. European Journal of Economic and Political Studies, Istambul, v. 7, p. 79-92, 2014.

LEOPOLDI, Maria Antonieta P. Política e interesses na industrialização brasileira: as associações industriais, política econômica e o Estado. São Paulo: Paz e Terra, 2000.

MAHONEY, James e Thelen, Kathleen (eds.). Advances in Comparative Historical Analysis. Cambridge, Cambridge University Press, 2015 : 3-38. P. 9).

MANCUSO, Wagner. P. O lobby da indústria no Congresso Nacional: empresariado e política no Brasil contemporâneo. São Paulo: EdUsp, 2007.

OLSON, Mancur. A lógica da ação coletiva: os benefícios públicos e uma teoria dos grupos sociais. São Paulo: EdUsp, 2011.

PANEBIANCO, Angelo. Modelos de Partido: organização e poder nos partidos políticos. São Paulo: Martins Fontes, 2005.

PERISSINOTTO, Renato M. Comparação, história e interpretação: por uma ciência política histórico-interpretativa. Revista Brasileira de Ciências Sociais, São Paulo, v. 28, n. 83, p. 151$240,2013$.

RAGIN, Charles C. A. The comparative method: moving beyond qualitative and quantitative strategies. Los Angeles: University of California Press, 1987.

SQUIRE, Peverill. Legislative Professionalization and Membership in State Legislatures. Legislative Studies Quarterly, v. 17, mai. 1992, p. 69-79. 
TOMIO, Fabrício R. DE L.; RICCI, Paolo. O Governo Estadual na Experiência Política Brasileira: os desempenhos legislativos das Assembleias Estaduais. Revista de Sociologia e Política, Curitiba, v. 21, n. 41, p. 193-217, 2012. 